\title{
Modeling of the investment project of construction the cottage settlement
}

\author{
Vladimir Malyuk ${ }^{1, *}$ and Aleksandr Danilov ${ }^{2}$ \\ ${ }^{1}$ Peter the Great St.Petersburg Polytechnic University, Polytechnicheskaya, 29, St. Petersburg, \\ 195251, Russia
}

\begin{abstract}
During implementing any project related to improving the financial and economic activities of the enterprise, creating a new product or technology, significantly improving the quality of the product or service being produced, investments and, first of all, financial investments are needed. The proposed article attempts to consider the process of investing in the implementation of a construction project in terms of its optimization, or at least rationalization. It is clear that the solution of this problem by conducting an economic experiment in the course of a realistic project carries an increased risk of the company losing capital. This risk is virtually eliminated if the experiment is carried out on the model. Today, undeservedly little attention is paid to economic and mathematical dependencies, built on the basis of S-models. In this article, we give a detailed example of the use of S-modelling in determining the rational volume of investments in the project of building a cottage community, identify the opportunities and problems of using such models, and identify areas for further research within the framework of the proposed topic.
\end{abstract}

\section{Introduction}

One of the essential characteristics of a modern organisation is the need for its continuous development. Any stagnation of this process might leat to the loss of competitiveness and independence in market activities [1]. Organisational development requires investment of a variety resources, the integral form of which is financial resources. Investing in organisational development be the implementation of a certain series of projects with specific goals, and evolved based on certain results of their implementation. It is clear that in conditions of total limited resources for organizational development, their investment in the project should be rational. The solution of this task is to ensure maximum efficiency in

\footnotetext{
* Corresponding authors: alexdanilov1993@gmail.com
} 
the use of resources allocated to the project, while using the principles of rational investment, some of which are presented in the source [2].

The task can be solved by marketing research for this type of product, price elasticity of demand, determining the necessary investment volume in the product, leading to the maximum result. Determining the optimal investments volume can be done by calculating the maximum possible paid demand for the results of production activity at different levels of the product price (a demand curve is constructed). After, break even analysis is carried out, break-even volumes are calculated, the volume of possible profit at different price levels for commodity products (project results). The maximum on the profit curve yields a rational profit-based "price-volume sales" proportion $[1,3]$.

Unfortunately, the approach which is stated earlier has several disadvantages. Sometimes it can prove to be very difficult to obtain the correct information about the current market,

and demand dynamics depending on prices value (at the same time real market experiments are very risky and can lead to profit loss). Information about current market state constantly changes [4]. Therefore, in such conditions the best approach is to create models based on economical-mathematical dependences. It could be different regression models, optimizational models, models that describe s-dependencies etc. The results that are aquaried throw such modeling processes can benefit the decision related to company development, project management and etc [5]. Forthemore modeling that is based on huge amounts of privious oppereational data deacreases risks of substantial financial losses.

\section{Materials and Methods}

During our investigation, we tried to apply methodical research, that uses s-modeling for the investment project. Such models allow us to calculate rational amount of investment and evaluate the scale of potential financial result $[6,7]$.

The calculations are based upon the imperical data of real business project. The project describes construction of a cottage settlement, in which the houses will be rented for a long time.

The type of the project - Timeshare. The service is called Timesharing, the same as Carsharing. Period of rent is limited by 30 years. The financial objectives of the project are oriented on getting $90 \%$ of the total amounts of possible rents in one year's time, at the income schould be arouund 300 millinon rubles. For simplicity one product value will be stated as one week of renting a cottage. The part of the project's business plan is in table 1 . Main goal of pre-project analysis is to determine realisitc size of investment project. The analysis heavily relays on s-modeling. It's clear that nowadays practical aplication of Smodeling is limited by weak methodological base and poor mathematical reasoning. [8,9].

$\mathrm{S}$-models describe broad scale of different processes that are related to great diversity of systems. S-modeling are good for explaining technical, social and social-economical processes. For example, process of enriching a fluid with another component, system's lifecycle, research investment in product efficiency or technological process could be described by models with saturation, s-models.

One of the main issues of organisational development is the problem of determining rational amount of investment to a project. Today this problem is being solved by experience alone, and by additional costs.

The main issue of such approach is that it's vey subjective and there's a high probability of a mistake. 
Table 1. Return of investment in Timesahre by quarter of a year during a six-year period.

\begin{tabular}{|c|l|l|c|l|l|}
\hline No & $\begin{array}{c}\text { X (quarter ex- } \\
\text { penses, cumula- } \\
\text { tively) 6 y., rub. }\end{array}$ & $\begin{array}{l}\text { Y (quarter } \\
\text { income, cumula- } \\
\text { tively) 6 y, rub. }\end{array}$ & No & $\begin{array}{l}\text { X (quarter expenses, } \\
\text { cumulatively) 6 y., } \\
\text { rub. }\end{array}$ & $\begin{array}{l}\text { Y (quarter income, } \\
\text { cumulatively) 6 y, rub. }\end{array}$ \\
\hline 1 & 16551294,9 & 0 & 13 & 287282548 & 386893420 \\
\hline 2 & 33102589,9 & 0 & 14 & 299512350 & 438820003 \\
\hline 3 & 49653884,8 & 0 & 15 & 301179653 & 438820003 \\
\hline 4 & 73756367,2 & 0 & 16 & 302846955 & 439479603 \\
\hline 5 & 117945427 & 20308913,1 & 17 & 304514258 & 441293503 \\
\hline 6 & 157566995 & 45695054,4 & 18 & 306181560 & 442447803 \\
\hline 7 & 181803390 & 86312880,6 & 19 & 307848863 & 442447803 \\
\hline 8 & 198258535 & 127590307 & 20 & 309516166 & 443107403 \\
\hline 9 & 223525838 & 180176489 & 21 & 311183468 & 444921303 \\
\hline 10 & 247893140 & 232103072 & 22 & 312850771 & 446075603 \\
\hline 11 & 261472943 & 282875355 & 23 & 314518073 & 446075603 \\
\hline 12 & 274602745 & 334307238 & 24 & 316185376 & 446735203 \\
\hline
\end{tabular}

On the other hand, the proposed approach is objective and consists of:

1. Given the information about possible total amount of investment, and it's rate we can make a prognosis about acommulative costs that are used in the project during it's enire lifetime and return of investment.

2. Based on obtained finanical flows we can constract imperical dependency $Y=f(X)$, where $\mathrm{Y}$ - return on investments, $\mathrm{X}$ - total accumulated investment. This dependancy is S-shaped (see fig. 1), that is explained by increase of return of investment on initial stages of the project and by following decrease of such return on the later stages. Such form of dependency refers to "The law of diminishing returns" [9,10], which states that starting with a certain point the efficiency of investment after crucial point decreases and reaches a near-rectilinear dependency (saturation), which states inefficiency of additional investments in the project.

3. S-dependency, built on imperical data, allowes us to write mathematical model relaying on Verhulst equation $[11,12]$

$$
y=\frac{A}{1+10^{a+6 X}}+C
$$

where, - A is the distance between the upper and lower asymptotes; - $\mathrm{C}$ is the lower asymptote or the limit from which the growth of the function $\mathrm{Y}$ begins; - $a$ and $b$ are the coefficients determining the slope and bending of the S-curve and its inflection point;

- $\mathrm{X}$ is an argument, the dependence on which the function $\mathrm{Y}$ is investigated;

- $\mathrm{Y}$ is the value of the function.

Thus, we got theoretically based dependency $Y=f(X)$. The obtained model, it seems to us, has a much deeper essence than only the dependence of one quantity to another. This model takes into account the most diverse characteristics of the organization, such as the level of personnel qualification and their focus on achieving the goals of organizational 
development, the nature of the technologies available in the organization and their level, the presence and nature of the machine system of the enterprise, etc. [13,14].

4. A straight line drawn from the origin at an angle of 45 is superimposed on the theoretical model of the S-curve, reflecting a directly proportional dependence of the return on investment on their volume and rates (see fig. 1). This straight line is collecting the points corresponding to break-even points, because it describes the equality of the volume of Investment made and their return [1,3]. As well known, straight line is discribed by liner equation $y=a+b x$, in the conditions of our metodics coefficient $\mathrm{a}=0, \mathrm{~b}=1$, that means we have dependency $Y=X$. As we can see (fig.1), S-curve and straight line, drawn from the origin at an angle of 45 intersect at three points, the first of which is a point with coordinates $(0 ; 0)$ in the future consideration we will not be interested, the second point of intersection is the payback point, which is determined using the known brake-even analysis technique and can be calculated from the formula:

$$
N_{B E P 1}=\frac{C_{p e r}}{P-C_{\text {var }}}
$$

where Cper and Cvar- conditional-constant and variable costs, respectively; $\mathrm{P}$ - price the unit price of the commodity product (the result of the project). Serious theoretical and practical interest is the third point of intersection of the investigated lines, this is the second break-even point $N_{B E P 2}$ (see fig. 1). This point is not defined for today, there is no method for calculating it.

5. The information obtained at the previous step allows us to draw conclusions. Investments in the implementation of a project with a volume of less than I1 (see fig. 1) are unlikely to yield a positive result, the return of funds invested in the project will not occur. The investment volume lying in the distance I1 - I2 (see fig.1), ensures their successful use and subsequent return to the investor. At the same time, the rates of return turn out to be different - at first they grow, then gradually fall to zero (a convex upward section of the Scurve) $[6,15,17]$. The interval is closed by volume 12 , which corresponds to the second payback $N_{B E P 2}$. Further increase in investment in the project, most likely, makes no sense, because return of investment can not be ensured (see fig. 1). Thus, it becomes possible to graphically determine the rational volume of investment, which lies in the interval I1 - I2 (see fig. 1). There is also a theoretical possibility of calculating these break-even points. For this it is necessary to solve the system of equations:

$$
\left\{\begin{array}{l}
Y=A+\frac{C}{1+10^{a+b X}} \\
Y=X
\end{array}\right.
$$

The second break-even point closes the interval of rational investment volumes, and its occurrence in some sources $[1,16]$ is explained by loss of project manageability with increasing its volumes, catastrophic increase in overhead costs in the course of project implementation due to growth of its scale, etc.

6 . On the revealed range of rational investment volumes in the project I1 - I2, it is necessary to determine the volume that gives the maximum return on investment. This investment in Figure 1 is designated as Iopt. The result obtained is the solution of the problem. The application of the above methodological approach to the actual implementation of the project provided some information for informed decision-making on the amount of investment in the project, but also revealed the problems associated with its use. Let's consider the practical implementation of this approach on the previously announced Timeshare project. 


\section{Results}

The first stage involves collecting the necessary analytical information, which is contained both in the business plan for the implementation of the project, and in the reporting documentation of the progress of the project. The result of the stage is the data collected in Table 1. The second stage concerns the construction of empirical dependence $Y=f(X)$. The construction is shown in fig. 1 in the form of a broken line.

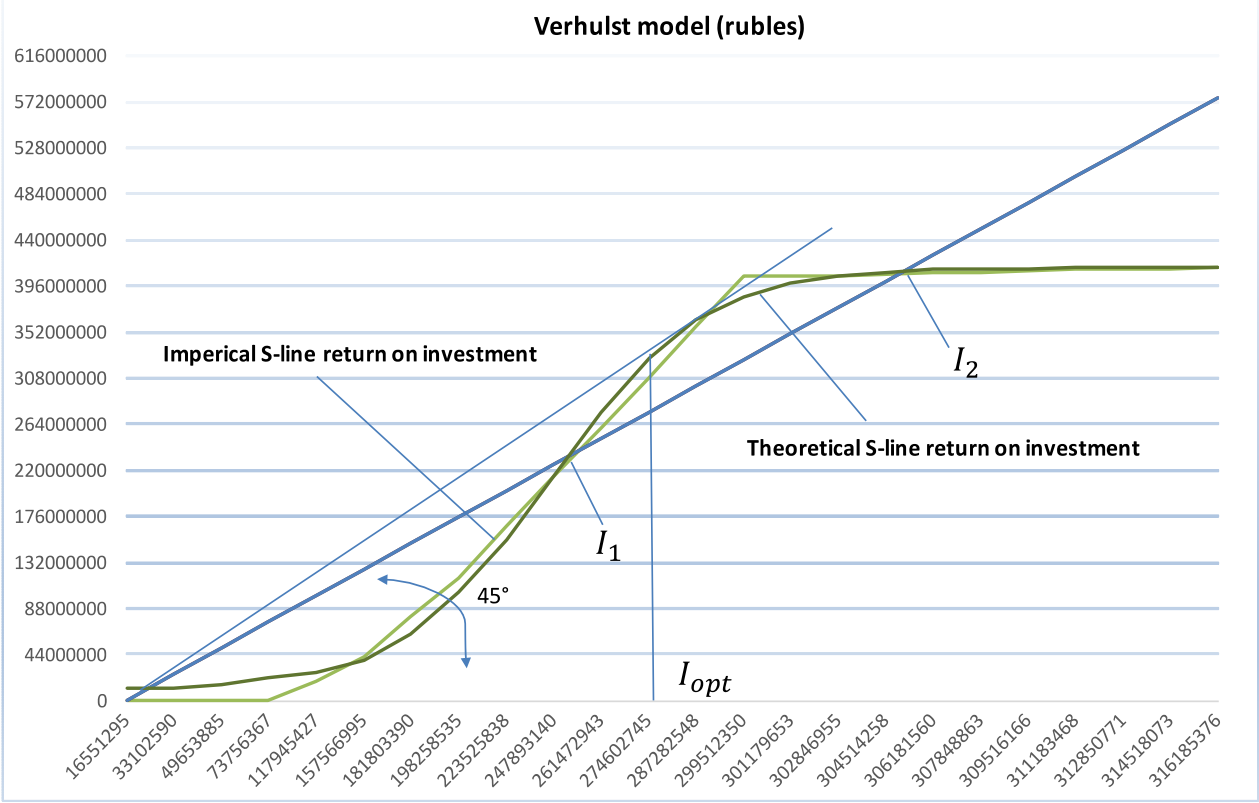

Fig. 1 Graphics of the dependence of return on investment based on empirical data

The third stage of the methodology assumes the formation of an economicmathematical model of dependence by selecting the coefficients in the Verhulst equation (formula 1), which reflects the dependencies with saturation. The classical form of this model is represented by the formula

$$
y=\frac{A}{1+10^{a+8 X}}+C
$$

If we assume the upper asymptote equal to $100 \%$ and combine the lower asymptote with the abscissa axis $\mathrm{X}$, then the Verhulst formula will acquire the following form, convenient for use

$$
y=\frac{1}{1+10^{a+6 X}}
$$

In the context of the problem being solved, the value of $\mathrm{X}$ is the investment in the project, and $\mathrm{Y}$ is the return on investment in the time under investigation. The corresponding results of calculations with tables of spreadsheets are presented in Table 2. 
Table 2. Estimated data for the construction of Verhulst models

\begin{tabular}{|l|l|c|c|c|c|c|c|}
\hline $\begin{array}{c}\text { Y(income } \\
\text { rub) }\end{array}$ & Y (Verhulst) & \multicolumn{1}{c|}{$\mathrm{A}$} & $\mathrm{a}$ & $\mathrm{b}$ & $\mathrm{X}$ & $\mathrm{C}$ & $\mathrm{b}^{*} \mathrm{x}$ \\
\hline 0 & 9796 & 446735203 & 5 & $-0,00000002$ & 16551294,9 & 0 & $-0,331025899$ \\
\hline 0 & 20993 & 446735203 & 5 & $-0,00000002$ & 33102589,9 & 0 & $-0,662051797$ \\
\hline 0 & 44987 & 446735203 & 5 & $-0,00000002$ & 49653884,8 & 0 & $-0,993077696$ \\
\hline 0 & 136472 & 446735203 & 5 & $-0,00000002$ & 73756367,2 & 0 & $-1,475127345$ \\
\hline 20308913,1 & 1042184 & 446735203 & 5 & $-0,00000002$ & 117945427 & 0 & $-2,358908549$ \\
\hline 45695054,4 & 6384670 & 446735203 & 5 & $-0,00000002$ & 157566995 & 0 & $-3,151339903$ \\
\hline 86312880,6 & 18936815 & 446735203 & 5 & $-0,00000002$ & 181803390 & 0 & $-3,636067804$ \\
\hline 127590307 & 38550290 & 446735203 & 5 & $-0,00000002$ & 198258535 & 0 & $-3,965170704$ \\
\hline 180176489 & 103714062 & 446735203 & 5 & $-0,00000002$ & 223525838 & 0 & $-4,470516755$ \\
\hline 232103072 & 215106923 & 446735203 & 5 & $-0,00000002$ & 247893140 & 0 & $-4,957862805$ \\
\hline 282875355 & 283433116 & 446735203 & 5 & $-0,00000002$ & 261472943 & 0 & $-5,229458856$ \\
\hline 334307238 & 339791053 & 446735203 & 5 & $-0,00000002$ & 274602745 & 0 & $-5,492054906$ \\
\hline 386893420 & 380029057 & 446735203 & 5 & $-0,00000002$ & 287282548 & 0 & $-5,745650957$ \\
\hline 438820003 & 406143906 & 446735203 & 5 & $-0,00000002$ & 299512350 & 0 & $-5,990247007$ \\
\hline 438820003 & 408889793 & 446735203 & 5 & $-0,00000002$ & 301179653 & 0 & $-6,023593058$ \\
\hline 439479603 & 411466060 & 446735203 & 5 & $-0,00000002$ & 302846955 & 0 & $-6,056939108$ \\
\hline 441293503 & 413881042 & 446735203 & 5 & $-0,00000002$ & 304514258 & 0 & $-6,090285159$ \\
\hline 442447803 & 416142959 & 446735203 & 5 & $-0,00000002$ & 306181560 & 0 & $-6,123631209$ \\
\hline 442447803 & 418259862 & 446735203 & 5 & $-0,00000002$ & 307848863 & 0 & $-6,15697726$ \\
\hline 443107403 & 420239608 & 446735203 & 5 & $-0,00000002$ & 309516166 & 0 & $-6,19032331$ \\
\hline 444921303 & 422089823 & 446735203 & 5 & $-0,00000002$ & 311183468 & 0 & $-6,223669361$ \\
\hline 446075603 & 423817881 & 446735203 & 5 & $-0,00000002$ & 312850771 & 0 & $-6,257015411$ \\
\hline 446075603 & 425430889 & 446735203 & 5 & $-0,00000002$ & 314518073 & 0 & $-6,290361462$ \\
\hline 446735203 & 426935671 & 446735203 & 5 & $-0,00000002$ & 316185376 & 0 & $-6,323707512$ \\
\hline
\end{tabular}

Based on the results of calculations, exponent in Table 2, it is possible to form the economic-mathematical dependence of the investigated quantities, which turned out to be the following

$$
y=\frac{1}{1+10^{5-0,210^{-7} X}}
$$

\section{Discussion}

According to the obtained model, we construct the S-curve on the same coordinate field, where there is an empirical curve (see Fig. 1). This will allow at least to visually assess the conformity of the models to each other. A more accurate estimate should be obtained in the process of comparing empirical and theoretical data series. The fourth stage of the investigation assumes the imposition on the obtained models of a straight line drawn from the 
origin of coordinates under 45 grade. The result of the construction is shown in Fig. 1 Graphics construction gives the first payback point equal to 261712450 (rubles)

Reported information on the value of the conditionally-constant and variable costs associated with the implementation of the Timeshare project was as follows: $C_{\text {per. }}=562116,49 \mathrm{rub} . C_{\text {var. }}=254433,21 \mathrm{rub}$. The price of a unit of the sold goods, at homeweeks, corresponds to $\mathrm{P}=655100$ rubles.

Substitution in the classical formula (2) numerical values by value within the framework of the implemented business plan yielded the following results

$$
\left.N_{B E P 1}=\frac{C_{p e r}}{P-C_{v e r}}=\frac{562116,49}{655100-254433,21}=399,5 » 400 \text { (week's }- \text { houses }\right)
$$

This number of rented weeks-houses corresponds to investments in the amount of

$$
I_{1}=P^{*} N_{B E P 1}=655100 * 400=26171245(r u b \text {. })
$$

As you can see, there is practically a coincidence of the graphically constructed payback point and its estimated value. The second break-even point as a result of the graphical construction in Fig. 1 turned out to be equal $I_{2}=304514258$ (rub.) . In the implemented business plan, the second breakeven point arose in the 17th quarter of the project implementation. The second break-even point closes the interval of rational investment volumes, and its occurrence in some sources $[1,16]$ is explained by loss of project manageability with increasing its volumes, catastrophic increase in overhead costs in the course of project implementation due to growth of its scale, etc.

\section{Conclusions}

Thus, the rational investment interval for the project I1-I2 was determined.

The fifth stage involves determining the boundaries of the rational investment interval by solving the system of equations

$$
\left\{\begin{array}{l}
y=\frac{1}{1+10^{5-0,2 \cdot 10^{-7} X}} \\
Y=X
\end{array}\right.
$$

However, the exact solution of the proposed system of equations, the first of which is transcendental, proved impossible. You should use methods that give approximate results, or use graphic constructions. That's what we did at this stage of methodological development. The sixth stage is connected with the determination on the revealed interval of rational volumes of investments in the project I1-I2 volume, which gives the maximum return on investment. This investment in Figure 1 is designated as Iopt. This result is the solution of the problem.

The direction of further research, in our opinion, is related to saturation, the search for acceptable solutions to the system of equations that determine the rational interval for investing in construction projects, incl. microdistricts of the city, settlements, other settlements, urban infrastructure projects, etc.

\section{References}

1. V.I. Malyuk, Strategic managment. Strategic organization development: tutorial and workshop for undergraduate and graduate (Moscow, Yurayt Publishing House, 2016) 
2. S. Grishunin, S. Suloeva, Lecture Notes in Computer Science, 9870 LNCS, 752-765, (2016).

3. I.V. Ilin, O.V. Kalinina, A.I. Levina, O.Y. Iliashenko. MATEC Web of Conferences. 86, 05028. (2016).

4. V.I. Malyuk, Modern problems of management: a textbook for undergraduate and graduate (Yurait publishing house, Moscow, 2017).

5. M.P. Vlasov, P. D. Shimko, The Modeling of economic processes (Spbgieu, SaintPetersburg., 2006).

6. V.I. Malyuk, Vest. ENGECON. Ser.: Econom., 2, 165-173, (2011).

7. V.I. Malyuk, Innovative economy and industrial policy of the region, ECOPROM2016, 222-227, (2016).

8. N.H. Trenev, Enterprise and its structure: Diagnostics. Management. Recovery. (Moscow, prior, 2010).

9. V.I. Malyuk, The problems of modern system management tools, Economy and industrial policies: theory and instrumentation, collective monograph. (Saint-Petersburg, 357-370, 2014).

10. G.S. Vechkanov Economic theory: Textbook for universities (Saint-Petersburg, Piter, 2011).

11. P.F. Verhulst, Recherches Mathématiques sur La Loi D'Accroissement de la Population, Nouveaux Mémoires de l'Académie Royale des Sciences et Belles-Lettres de Bruxelles, 18, Art. 1, 1-45, (1845).

12. B.A. Anikin, Logistics workshop: Studies. the allowance, (Moscow, INFRA-M, 2007).

13. V.I. Malyuk, K.P. Goloskov, Bulletin of ENGECON., Ser.: Economics, 2(21), 45-53 (2008).

14. V.I. Malyuk, E.A. Smirnova, Vestnik of ENGECON., Ser.: Economics., 5(72), 1420, (2014).

15. V.I. Malyuk, Scientific and technical sheets of Saint-Petersbug Polytechnical University, 4(223), 167-174 (2015).

16. V.I. Malyuk, Region. economy: theory and practice, 18, 12-21, (2009).

17. A.A. Danilov, V.I. Malyuk, SPbGPU science week, IIMET, part1, 45, 410, (2016). 